\title{
A CIDADE EDUCADORA, UMA ESTRATÉGIA PARA \\ A INCLUSÃO DAS PESSOAS COM DEFICIÊNCIA \\ UM FUTURO DESEJÁVEL E UM PROCESSO DE MUDANÇA EM CURSO
}

The Educating City, a Strategy for the Inclusion of People With Disabilities. A Desirable Future and an Ongoing Process of Change

\section{Domingos Rasteiro \\ Instituto Politécnico Jean Piaget do Sul drasteiro@sapo.pt}

RESUMO: Sabemos hoje as potencialidades que a educação tem nos processos de mudança das pessoas, das organizações e das sociedades e, nesse pressuposto, o principal objetivo deste artigo é explorar a temática da educação nas cidades, ligando esse domínio à problemática das pessoas com deficiência. Nesse quadro apresentam-se os resultados de um trabalho de investigação que foi realizado entre 2015 e 2017 e teve como foco as cidades portuguesas associadas da Associação Internacional das Cidades Educadoras (AICE). As cidades que participaram no estudo foram 31 , de um universo de 57 , sendo possível, através do estudo das perceções dos dirigentes políticos e dos técnicos dos municípios, construir um «ranking» do potencial inclusivo das cidades. A realização de dois estudos de caso nas cidades com melhor potencial inclusivo permitiu determinar quais os fatores que influenciam as políticas de inclusão que desenvolvem, tendo como preocupação a melhoria da qualidade de vida das pessoas com deficiência, servindo de indicação para boas práticas inclusivas.

PalaVras-chave: cidades educadoras, cidades inclusivas, inclusão social, pessoas com deficiência

RESUMEN: Sabemos hoy las potencialidades que la educación tiene en los procesos de cambio de las personas, de las organizaciones y de las sociedades 
$y$, en ese supuesto, el principal objetivo de este artículo es explorar la temática de la educación en las ciudades, vinculando ese dominio a la problemática de las personas con discapacidad. Esta tabla presenta los resultados de un trabajo de investigación que se llevó a cabo, centrándose en las ciudades portuguesas asociados con la Asociación Internacional de Ciudades Educadoras (AICE), que tuvo lugar entre 2015 y 2017. Las ciudades que participaron en el estudio fueron 31 de un universo de 57 , siendo posible a través del estudio de las percepciones de los dirigentes políticos y de los técnicos de los municipios, construir un "ranking" del potencial inclusivo de las ciudades. La realización de dos estudios de caso en las ciudades con mejor potencial inclusivo permitió determinar cuáles son los factores que influencian las políticas de inclusión que desarrollan, teniendo como preocupación la mejora de la calidad de vida de las personas con discapacidad, sirviendo de indicación para buenas prácticas inclusivas.

Palabras clave: ciudades educadoras, ciudades inclusivas, inclusión social, personas con discapacidad.

RESUM: Sabem hui les potencialitats que l'educació té en els processos de canvi de les persones, de les organitzacions i de les societats i, en aqueix supòsit, el principal objectiu d'aquest article és explorar la temàtica de l'educació a les ciutats, vinculant aqueix domini a la problemàtica de les persones amb discapacitat. Aquesta taula presenta els resultats d'un treball de recerca que es va dur a terme, centrant-se en les ciutats portugueses associats amb l'Associació Internacional de Ciutats Educadores (AICE), que va tindre lloc entre 2015 i 2017. Les ciutats que van participar en l'estudi van ser 31 d'un univers de 57 , sent possible a través de l'estudi de les percepcions dels dirigents polítics i dels tècnics dels municipis, construir un "rànquing" del potencial inclusiu de les ciutats. La realització de dos estudis de cas a les ciutats amb millor potencial inclusiu va permetre determinar quins són els factors que influencien les polítiques d'inclusió que desenvolupen, tenint com a preocupació la millora de la qualitat de vida de les persones amb discapacitat, servint d'indicació per a bones pràctiques inclusives.

Paraules clau: ciutats educadores, ciutats inclusives, inclusió social, persones amb discapacitat. 


\begin{abstract}
Today we are aware of the potential education has in the process of change for people, organizations and societies. Based on this assumption, the main objective of this article is to explore the theme of education in cities in connection with the issue of people with disabilities. Within this frame we present the results of research carried out between 2015 and 2017 with a focus on the Portuguese member cities of the International Association of Educating Cities (IAEC). A total of 31 cities from a universe of 57 took part in the study. Through the study of the perceptions of political leaders and specialist city council staff, the cities were ranked according to their inclusive potential. Case studies were carried out on the two highest ranking cities in order to identify the factors that influence the inclusion politics developed in the cities, aimed to improve the quality of life of people with disabilities, and provide an indication of good inclusive practices.
\end{abstract}

KEYWORDs: Educating cities, inclusive cities, social inclusion, people with disability.

\title{
I. Contextualização da problemática
}

Este artigo tem por objetivo divulgar um trabalho de investigação que se centrou no problema da inclusão social das pessoas com deficiência nas cidades e sobre a importância que a educação tem na vida das cidades que procuram ser mais equitativas e que fomentam a igualdade de oportunidades. Desde os anos noventa que a problemática da inclusão tem sido um tema fundamental nos processos de dignificação social deste grupo específico, cuja marginalização tem sido uma constante histórica, embora se verifique uma evolução a partir de uma perspetiva terapêutica do problema para uma perspetiva educativa e social. Mais determinante na mudança em curso é o entendimento de que a integração social depende menos das capacidades dos indivíduos e mais do envolvimento e do contexto social.

Nas últimas décadas emergiram um conjunto de fatores que contribuíram para um progresso na conquista dos direitos da cidadania e da inclusão social, nomeadamente o avanço das ciências e da saúde, os movimentos de 
renovação e de inovação, como sejam a desinstitucionalização e a educação inclusiva, bem como os avanços sociais, no que se refere ao reconhecimento dos direitos e às novas oportunidades de participação na sociedade.

Essa evolução foi criando condições para a emergência de um conceito mais amplo de sociedade inclusiva, reconhecendo-se que não basta haver uma boa inclusão na escola ou na família, sendo necessário que toda a sociedade se possa ajustar às necessidades das pessoas que a compõe. Numa conferência realizada em Lisboa, de 26 a 29 de julho de 2015, sobre o tema «Equidade e Inclusão na Educação», Mel Ainscow chamava a atenção para o facto de a inclusão na escola ser muito importante, pela simples razão de que se tem de começar por algum lado, no sentido de um maior respeito pelos direitos das pessoas com necessidades especiais e no desenvolvimento de um processo, em que se alcance um lugar social de maior equidade nas sociedades contemporâneas para as pessoas com necessidades especiais. No reforço desta posição, a própria Declaração Final do congresso, intitulada Declaração de Lisboa Sobre Equidade Educativa (2016), refere, ao enumerar as razões que justificam as escolas inclusivas, que existe uma justificação social que se prende com o facto de as escolas inclusivas serem capazes de mudar atitudes face à diferença, ao educarem todas as crianças conjuntamente, sendo que, dessa forma, ajudam a construir uma sociedade acolhedora, participativa, justa e não discriminatória.

O enquadramento social das pessoas com deficiência tem evoluído de modelos que culpabilizam os próprios sujeitos pelas suas diferenças funcionais, para modelos que se focam nas transformações que se podem promover no contexto para aumentar a funcionalidade e os níveis de participação social. Foram décadas de luta pelos direitos sociais que estão hoje consagrados nas principais Cartas Constitucionais e na legislação e que reconhecem que, independente das características específicas das pessoas, que não devem ser escamoteadas, é às sociedades que cabe promover as mudanças, os ajustamentos e as adaptações que permitam a igualdade de oportunidades e a participação de todos na vida coletiva aos mais diversos níveis.

Esta nova perspetiva ficou bem patente aquando da aprovação da Convenção Sobre os Direitos das Pessoas com Deficiência pela Assembleia das Nações Unidades, em 13 de dezembro de 2006. Este documento foi assinado 
por 164 países que se comprometeram a implementá-la. Vários aspetos deste documento ajudam a clarificar o problema deste estudo, na medida em que definem metas e objetivos que devem estar subjacentes às políticas seguidas, às medidas adotadas e às ações que as concretizem. Logo no artigo $3 .^{\circ}$ são definidos um conjunto de Princípios Gerais, tais como o respeito pela dignidade inerente à autonomia individual, a não discriminação, a participação e inclusão plena e efetiva na sociedade, o respeito pela diferença, a igualdade de oportunidades e a acessibilidade.

Ficaram consagrados na Convenção, com o compromisso dos governos promoverem essas transformações, aspetos como a acessibilidade aos espaços físicos, aos edifícios, à informação e às tecnologias; o direito a viver de forma independente e a ser incluído na comunidade, evitando a segregação e disponibilizados os recursos e meios adequados; a mobilidade pessoal, no sentido de favorecer a independência pessoal e a autonomia na vida quotidiana; a liberdade de expressão e de opinião e o acesso à informação, incluindo a utilização de meios aumentativos e alternativos de comunicação, bem como o fornecimento de serviços acessíveis; a educação e o reconhecimento do direito ao pleno desenvolvimento do potencial humano, o acesso à saúde, ao trabalho, assim como a participação na vida política e pública, garantindo condições de igualdade nos direitos cívicos e políticos, o direito de expressão da vontade e dos interesses, encorajando-se, por todos os meios, a participação nos assuntos públicos.

Um dos pontos centrais do problema, que nos mobilizou para a investigação, relacionou-se com a real concretização destes direitos nas sociedades contemporâneas, ou seja, com o modo como se concretiza nas cidades a implementação dos direitos consagrados na Convenção. Será que se está a construir esse caminho? Quais são as formas possíveis de o concretizar, ao nível das cidades e das suas políticas públicas?

Interessa, passada que foi mais de uma década após a aprovação da Convenção, e de avanços significativos ao nível da educação inclusiva nos últimos anos, com variados exemplos de boas práticas nas escolas, que se possa abrir caminho, ao nível de outros sistemas, como é o caso das comunidades locais. O que está em causa, no sentido do pleno exercício dos direitos e dos deveres de cidadania, é o facto desta temática não poder nem dever ficar 
circunscrita às famílias e às escolas, pelo que deverá ganhar dimensões mais globais, de construção de uma sociedade inclusiva. Só deste modo, através do respeito pelos direitos humanos, da participação na sociedade e do acesso às diferentes oportunidades sociais, se poderá falar de igualdade de direitos e oportunidades.

Os problemas que se colocam na atualidade não são, como em tempos anteriores, a carência de uma ação terapêutica, reabilitativa, assistencial centrada nos indivíduos. Vai muito para lá disso. O que está em causa é uma abordagem mais global que olhe para as pessoas no seu todo e no seu contexto social, familiar e económico. Sassaki (2003) chama a atenção para isso quando refere que a inclusão social implica um caminho de respeito pelos direitos humanos, de solidariedade, de melhoria da qualidade de vida, de equidade e de igualdade de oportunidades. É sabido que no continente europeu cerca de 80 milhões de pessoas são discriminadas pelas suas características específicas, sendo que dois terços não têm acesso a uma oportunidade laboral, a taxa de desemprego é três vezes superior à da população em geral, estão afastados dos bens que a comunidade disponibiliza por questões económicas e de acessibilidade e o seu nível de participação social e de exercício da cidadania é muito restrito.

Para que se possa alterar este estado de coisas, Lorenzo (2005) faz apelo às referências e às potencialidades da inclusão social que poderão contribuir para um maior protagonismo das pessoas nas decisões sobre a sua própria vida, a necessidade de, por essa via, terem uma maior visibilidade social, a importância que pode assumir a corresponsabilização da sociedade e das suas instituições nesse processo, na possibilidade dos processos de inclusão poderem gerar a mobilização de novos recursos públicos, privados e associativos e nas condições que possam vir a ser criadas para a acessibilidade global aos bens comunitários e a uma vida com mais dignidade.

O trabalho de investigação que foi desenvolvido é um contributo para o aprofundamento dos direitos humanos, como uma forma de se explorarem oportunidades para favorecer a igualdade de oportunidades e a equidade, dando maior visibilidade a um problema que exige uma abordagem ao nível da inclusão social, nas suas diversas dimensões, contrariando a ideia de que a diferença implica a marginalização e a exclusão. O principal objetivo foi o 
de cruzar a problemática da inclusão social das pessoas com deficiência com a vida nas cidades, tendo em conta que é no espaço da cidade, dos bairros, do espaço público, dos serviços disponíveis e das oportunidades, que se oferecem melhores condições para o desenvolvimento humano. Muito se poderá fazer, ainda, para favorecer maiores níveis de inclusão, facilitando as trocas sociais, a socialização, as experiências culturais, laborais de lazer e de cidadania. Segundo Bohigas (2013), as cidades desempenham um conjunto de funções civilizacionais:

La ciudad es un artefacto artificial de ladrillos, cemento, pavimento, árboles, etc. construida para que la gente pueda vivir en ella, para dar facilidades a la convivencia y a la creación, de interrelaciones entre la colectividad. Es un artefacto absolutamente artificial contra natura y a favor de unas actitudes civilizadoras. (p. 21).

Esta é uma abordagem pertinente na medida em que o mundo é cada vez mais urbano. Prevê-se que nas próximas três décadas o número de pessoas a viver nas cidades duplique, aproximando-se dos cinco mil milhões de indivíduos, ou seja, cerca de $3 / 5$ da população mundial. A qualidade de vida das pessoas, o desenvolvimento socioeconómico, o conhecimento e a aprendizagem, o exercício dos valores, o exercício da cidadania e da democracia jogam-se muito nas dinâmicas sociais das cidades. Cidades que, por natureza, são espaços da diferença, da complexidade, da contradição de interesses e do exercício de poderes. Desafios que se colocam à cidade como espaço coletivo de cidadania.

Segundo Teixeira (2015), citando o National Intelligence Council dos Estados Unidos, todos os anos 65 milhões de pessoas juntam-se à população urbana mundial, o que significa uma quantidade de população que equivale a sete cidades do tamanho de Chicago ou a cinco do tamanho de Londres. Refere, também, que $54 \%$ da população mundial vive em áreas urbanas, sendo que a média na Europa é de $70 \%$ de pessoas a viver em cidades.

No entanto, as cidades são também lugares geradores de conflitos de interesses, de insegurança, de exclusão, de pobreza e de marginalização dos mais desfavorecidos. Uma das maiores dificuldades apontadas pelas pessoas com deficiência são as desajustadas infraestruturas existentes e a falta de condições para a participação na vida das cidades. As barreiras à participação, 
segundo Sassaki (2003), podem ser: i. barreiras arquitetónicas (de teor físico - rampas, quartos inadaptados); ii. comunicacionais (a linguagem utilizada não é percetível por todos); iii. atitudinais (baseadas em atitudes preconceituosas); iv. metodológicas (métodos de ensino, trabalho e lazer homogéneos); v. instrumentais (os instrumentos utilizados no quotidiano não são os mais adequados), pelo que as grandes mudanças que se preconizam vão no sentido de promover a cidadania das pessoas com deficiência, organizar campanhas que favoreçam a integração social, favorecer o acesso à informação e à convivência social e aos serviços considerados imprescindíveis, criar serviços de apoio à vida diária, adaptar os edifícios e os espaços públicos, favorecer a mobilidade e o transporte, promover estudos e trabalhos de investigação que ajudem no diagnóstico e nas respostas às necessidades e promover planos de ação que concretizem as várias medidas necessárias para adaptar as cidades e as populações com diversidade funcional.

\section{A educação e inclusão nas cidades}

A educação nas cidades é, sem dúvida, uma forma de as tornar mais inclusivas, sendo uma maneira de responder aos desafios da vida em comum, de que são lugar privilegiado, pois as cidades são laboratórios vivos de aprendizagem da vida coletiva, lugares de educação permanente, em que múltiplos agentes e entidades põem em prática os seus ideais de educação e de vida económica, cultural, artística e espiritual. Fazer de uma cidade, cidade educadora e cidade inclusiva é procurar um lugar melhor para o desenvolvimento humano, nas suas dimensões de vida material e imaterial.

Os processos educacionais que se geram nas cidades são determinantes para a construção de um espaço territorial propício à inclusão. Se tivermos em conta que os processos educacionais dependem sempre da interação dos indivíduos com o meio envolvente, então, compreenderemos, facilmente, que isso não se verifica apenas na escola ou na família, mas também se aplica à comunidade em que vivemos e ao espaço territorial e urbano.

Assim sendo, a cidade educadora enquadra-se no que poderia ser designado como educação não escolar, no dizer de Trilla (1999), no pressuposto de que 
as influências da educação estão para além da escola e da família, pois as influências que se recebem do meio são, tão ou mais marcantes, do que as que se recebem das instituições que mais tradicionalmente estão associadas aos processos educativos.

Neste quadro de referência, no estudo levado a cabo foi dada importância ao facto de se estudarem fenómenos que, emergindo de novas linhas da investigação em educação, ligam a educação aos grandes temas da atualidade e se centram em campos como o da educação informal e não formal ou social. A educação não formal e informal na definição de Trilla (2006) devem ser entendidas como:

[...] el conjunto de procesos, medios e instituciones específica y diferencialmente diseñados en función de explícitos objetivos de formación o de instrucción, que no están directamente dirigidos a la provisión de los grados propios del sistema educativo reglado. (p. 206)

[...] referirse a aquellos procesos educativos que se producen sen especificación e indiferenciados doutros procesos sociais, que non foron institucionalizados nin sistematizados, que se dan no curso ordinario da vida. (p. 206)

Os processos de sociabilidade, os valores que transmitem, as oportunidades que se geram, os modos de comunicação e os recursos disponíveis fazem dos territórios aquilo que, desde a década de noventa, Faure (1972) designou por cidades educativas. Ideia corporizada por Marta Mata, em 1989, na cidade de Barcelona que viria a estar na origem do movimento internacional das cidades educadoras.

Neste quadro de referências o que se pretende é que na gestão das cidades se promova o melhor crescimento possível, se potencializem as capacidades das pessoas e dos grupos humanos, se fomentem as interações entre as pessoas e as organizações sociais, gerando, a partir desses processos, um valor educativo que favoreça o progresso individual e social. Esta é a definição que Del Pozo (2013) nos propõe de cidade educadora e que coloca em destaque a capacidade de interagir com os cidadãos, através de processos que gerem a mudança dos indivíduos e das comunidades. 
Quando se aborda a temática da educação e da inclusão das pessoas com deficiência, o que está em causa é a construção de uma comunidade aberta, participativa e interveniente, em que os direitos individuais dos cidadãos se compatibilizem com o desenvolvimento global da comunidade, respeitando as suas diferenças, mas numa lógica universalista, valorizando mais o que temos em comum do que aquilo que os torna diferentes. Entende-se a comunidade e o território como recursos que podem compensar as dificuldades, as diferenças e as carências, num processo de enriquecimento que parte da mobilização de todos os atores, de todas as instituições e dos cidadãos, num exercício vital da cidadania ativa.

Em novembro de 2014, realizou-se em Barcelona o Congresso Internacional das Cidades Educadoras 2014, que teve como tema «Uma cidade Educadora é uma Cidade que Inclui». Como se refere na declaração final do congresso, ao fim de 20 anos da fundação desta Associação Internacional, em que as cidades se afirmam como fortes polos de aprendizagem e de participação dos cidadãos, mobilizando os responsáveis políticos para os problemas que os afetam, num tempo histórico em que as sociedades atravessam um conjunto de novas e complexas questões que interferem com a vida das populações.

Neste contexto foi importante que nas conclusões do referido Congresso os países e os governos locais assumiram o compromisso de favorecer a inclusão nas cidades através de propostas concretas, potencializando as políticas de inclusão social que abranjam as diferentes áreas de intervenção comunitária, criando diferentes serviços sociais necessários para os grupos mais vulneráveis; de promover e fomentar projetos educativos com utilidade social, que associem a aprendizagem com o serviço à comunidade, estimulando a cidadania e promovendo a transformação e melhoria de vida. Proponha-se a potencialização do trabalho em rede e a participação dos cidadãos. A criação de condições de acessibilidade, através de transportes públicos adaptados às diferentes necessidades. A construção de uma cidade sem barreiras físicas e de segregação social

Neste quadro, a educação assume uma nova linguagem, conforme refere Biesta (2005), que permite pensar e agir de forma mais abrangente a educação, não reduzindo esse domínio do saber aos resultados da aprendizagem, 
aos métodos de ensino ou aos aspetos tradicionalmente tratados nesta área, assumindo que a educação é definitivamente uma estratégia de mudança e de transformação.

Conforme chama a atenção Alves e Azevedo (2010):

Importa entender a Educação numa perspetiva mais holística e abrangente, segundo a qual a mesma extravasa as fronteiras dos espaços formalizados de ensino-aprendizagem para se confundir numa perspetiva antropocêntrica com a própria construção da pessoa que protagoniza ativamente um processo educativo que se desenrola ao longo e ao largo da vida e que é inerente à própria existência humana. (p. 5)

Federico Mayor (ex-diretor-geral da UNESCO) salientava que a educação é a força do futuro na medida em que se constitui como um dos mais poderosos instrumentos para promover as mudanças e as modificações que se tornam necessárias, sendo que um dos desafios maiores será o de modificar o nosso pensamento acerca do modo como vamos enfrentar a complexidade, a rapidez das transformações e o imprevisível que caracteriza os tempos e os lugares onde vivemos. Uma resposta possível a estas preocupações de Federico Mayor estará na Declaração de Incheon - Educação 2030/Unesco - «Rumo a uma educação de qualidade inclusiva e equitativa e à educação ao longo da vida para todos»», ou seja, reafirmar a educação como um bem público, ao alcance de todos, como uma forma de consolidar os direitos humanos, através da promoção da equidade e da inclusão.

Nesta perspetiva, a educação é vista como uma política social de generalização da igualdade de oportunidades, reforçando o papel dos Estados nas suas diferentes componentes de governos centrais, locais e regionais, como garante da educação como um direito social e humano básico. É neste quadro que se pode definir o movimento das cidades educadoras, que procuram ser uma referência para as cidades que estão empenhadas neste processo permanente de olharem para o sistema educativo ${ }^{1}$, partindo de uma leitura das

1. O sistema educativo definido na Lei de Bases, Lei 44/86, de 14 de outubro, conforme artigo $1 .^{\circ} \mathrm{n} .^{\circ} 2$, é o conjunto de meios pelo qual se concretiza o direito à educação, que se exprime pela garantia de uma permanente ação formativa orientada para favorecer o desenvolvimento global da personalidade, o progresso social e a democratização da sociedade. 
necessidades locais e das expectativas das suas comunidades. Como é referido por Fernandes (s. d.):

Ao chamar-se a atenção para o papel educativo da cidade, há uma instituição que é convocada para assumir um papel de liderança na coordenação e dinamização de uma política educativa com base neste espaço urbano: essa instituição é o município. (p. 2)

É na proximidade com os problemas e com as potencialidades que os municípios têm desenvolvido as suas políticas, numa certa tensão entre o que lhes é exigido pelo exercício das suas competências específicas, que derivam da lei, e o sentido de responsabilidade que advém do exercício da cidadania e que colocam problemas novos e necessidades prementes a que urge dar resposta.

Assim, têm sido promovidas muitas das políticas de bem-estar, da educação, da saúde e dos serviços sociais que, estando para além da dimensão universal das respostas, procuram soluções heterogéneas para situações que emergem do quotidiano da vida das comunidades. Foi desse modo que muitos municípios portugueses, nas últimas quatro décadas, foram o veículo de acesso a uma vasta gama de recursos formativos, como a música, as artes, o conhecimento da história e do património local, o fomento dos projetos educativos, o apoio às associações de pais e o reforço do seu papel na vida das escolas, contrabalançando as competências legais com as competências reais. Sobre esta matéria pode-se atentar no que diz Del Pozo (2003):

Si lo que se pretende es promover un compromiso fuerte de la administración con el gran reto social de la educación, no podemos limitarnos - los Ayuntamientos - a perspectivas gestionarlas o administradoras del hecho educativo, sino que hemos de incorporarnos activamente al debate político y legislativo sobre cuestiones pedagógicas y sociales. (p. 3)

A cidade, na sua função educadora, assume o meio como contexto favorável à formação. Procura propostas integradoras e entende a educação como um domínio que ganha, no espaço territorial, uma dimensão integrada e permanente. $\mathrm{Na}$ verdade, o processo educativo depende muito de tudo aquilo que rodeia a pessoa humana, como já referimos, e nas aceções desenvolvimentistas esses processos estão muito dependentes da interação do sujeito 
com o meio físico e social envolvente. Daí que, quanto mais significativo for o meio, quantos mais estímulos e experiências ele proporcionar, melhor serão os processos educativos que nele ocorrem. Nesta abordagem, o território é algo mais do que um espaço físico, é investido de representações políticas, culturais, sociais e educacionais que se tornam a base material, o espaço das relações sociais que nele ocorre.

O território não é apenas o resultado da superposição de um conjunto de sistemas naturais e um conjunto de sistemas de coisas criadas pelo homem. $\mathrm{O}$ território é o chão e mais a população, isto é, uma identidade, o fato e o sentimento de pertencer àquilo que nos pertence. $\mathrm{O}$ território é a base do trabalho, da residência, das trocas materiais e espirituais e da vida, sobre os quais ele influi. (Santos, 2008: 96)

Para que esse conceito de território, como espaço educativo, possa emergir, se possa consolidar, é necessário que exista um sentimento de vínculo e pertença das populações, ou seja, que as ações se destinem e se desenvolvam em ordem às características específicas do território e que respondam, nessa medida, às necessidades e expectativas intrínsecas dessa comunidade. Esta construção social só é possível com políticas educativas de proximidade, de relação com os atores locais, que visam a construção de uma territorialidade socioeducativa, distinguindo-se, por isso mesmo, das políticas nacionais que visam atingir objetivos de universalidade. Daí a importância das políticas locais de educação que, em última análise, se podem sintetizar nos desígnios das cidades educadoras.

\section{A educação como estratégia de mudança das cidades}

Como refere Merino (2007), acerca das principais características das cidades educadoras, as mesmas estão relacionas com a mobilização das pessoas, dos habitantes para os processos de educação:

[...] la característica más significativa de las ciudades educadoras: la voluntad de transformación social desde la educación y de apostar por la voz de las personas como los verdaderos actores sociales de la transformación. En las ciudades que forman parte de la red de ciudades educadoras se ha debatido, se ha 
propuesto, se ha discutido, rebatido y se han definido estrategias consensuadas para la educación que marcan un cierto camino a seguir. (p. 10)

Se considerarmos que o território educativo é uma construção coletiva de uma dada comunidade humana, então isso significa que se devem promover processos que corporizem essa expressão da vontade e da responsabilidade dos cidadãos e das organizações de um dado território. Esse é o enfoque das cidades educadoras que procuram mobilizar os cidadãos, as organizações, os agentes políticos para a inclusão de todos na cidade. Como refere Martin (2007):

Parafraseando la definición de Ainscow y otros (1994) de escuela inclusiva, podríamos entender que una ciudad inclusiva es aquella en la que cualquier persona puede llevar a cabo un proyecto de vida independiente y participar plenamente en la vida política, social y económica con igualdad de oportunidades en relación con el resto de los miembros del grupo social. (p. 61)

Este é ponto de cruzamento entre as cidades educadoras e as cidades inclusivas. No reforço dos poderes formais e informais dos municípios que, pelo facto de estarem muito próximos das populações, têm um forte potencial para desenhar as soluções, programar as ações, estruturar os serviços públicos, adaptando-os às necessidades específicas de cada comunidade. Nesta base poder-se-ão desenvolver projetos de cidade que conjuguem as dinâmicas educativas locais com uma cidade para todos, com uma cidade inclusiva, potenciando as ligações da educação com a cidade, num trabalho em rede corresponsável entre os atores locais e os diferentes agentes de desenvolvimento.

Citando de novo Martin (2007), deve ter-se em conta que a cidade é uma unidade adequada para promover a inclusão. Esse processo implica que se crie um espaço, um produto e um conjunto de serviços que sejam acessíveis a todos os cidadãos, pelo que os autores propõem:

El movimiento de escuelas inclusivas elaboró hace ya casi diez años un instrumento para evaluar las barreras de los centros escolares y los avances que se iban produciendo en su eliminación. Se trata del Index for Inclusion propuesto por Booth y Ainscow (2000). Este instrumento permite a la comunidad escolar tomar conciencia de aspectos de la realidad que de otra forma podrían pasar desapercibidos. Desde nuestro punto de vista, tendría mucho interés elaborar un 
instrumento semejante para valorar los avances en la inclusión de las ciudades, un Index de ciudades inclusivas. (p. 63)

A cidade inclusiva é um lugar onde todos, independentemente dos seus meios económicos e do género, da raça, da etnia ou da religião e das condições físicas e mentais, estão habilitados e capacitados para participar plenamente nas oportunidades sociais, económicas e políticas que as cidades têm para oferecer. O planeamento participativo da tomada de decisões é o centro da cidade inclusiva. Balbo, M., Jordán, R., e Simioni, D. (2003), para a definir, fundamentam-se na definição das Nações Unidas (2000) que identifica a cidade inclusiva como:

O lugar onde qualquer pessoa, independentemente de situação económica, sexo, idade, raça ou religião, tem possibilidades de participar de forma produtiva e positivamente nas oportunidades que a cidade tem para oferecer. (p. 310)

Como se sabe, a cidade como espaço de diversidade não é vivida por todos do mesmo modo. Existem, mesmo, grupos sociais que estão excluídos de desfrutar da cidade ou, então, fazem-no de forma precária. Muitas pessoas, por via da especificidade das suas necessidades, não podem sair de casa, não podem circular pelo espaço público, não participam na vida cívica. Entre esses grupos podemos incluir as pessoas com deficiência que, não encaixando nos padrões ditos da normalidade, ficam impedidas de viver as mesmas experiências e de partilhar os mesmos recursos. Para que a diferença não se transforme em exclusão é necessário a reconfiguração das cidades, o que implica decisão política e mudança das práticas, desenvolvendo formas de devolver às pessoas com deficiência os seus direitos à cidadania, os seus direitos humanos.

\section{Estudo centrado nas cidades portuguesas associadas da AICE}

\subsection{Objetivos}

Foi no pressuposto que as cidades educadoras podem favorecer processos educativos e sociais que tornem os territórios, as dinâmicas sociais e a interação entre os atores sociais mais favoráveis à inclusão social que se levan- 
taram um conjunto de interrogações: Quais são os fatores que nas cidades impulsionam as políticas e as medidas que as tornem mais inclusivas? Qual o papel dos governos locais na dinamização e no desenvolvimento dessas políticas? Qual a participação da sociedade e das suas organizações nesse processo, nomeadamente, das organizações representativas das pessoas com deficiência? Quem são os principais dinamizadores dos projetos socioeducativos levados a cabo nas diferentes cidades? Que resultados concretos são obtidos com a implementação dessas medidas para o aumento do nível de participação dos cidadãos na vida das comunidades? Serão essas medidas de carácter duradouro ou meramente temporário? Como se expressam no terreno e na realidade a concretização das políticas inclusivas, nomeadamente, tendo em conta a vida quotidiana das pessoas com necessidades especiais?

Foi este conjunto de interrogações que estiveram subjacentes à procura de uma pergunta aglutinadora que pudesse ser o motor do trabalho de investigação e dos objetivos que procuram dar substância operacional ao trabalho e que se enunciam de seguida. Nessa perspetiva, a pergunta de partida do nosso estudo foi: Como se promovem políticas inclusivas nas cidades que fomentem a equidade de acesso aos recursos e às oportunidades educativas, culturais e sociais aos cidadãos com necessidades especiais?

A investigação, conforme Rasteiro (2017), centrou-se nas cidades portuguesas que fazem parte da Rede Internacional das Cidades Educadoras. Este critério prende-se com o facto de essas cidades terem assinado a Carta das Cidades Educadoras em que se encontram muitas justaposições com o objetivo da inclusão das pessoas excluídas. O trabalho desenvolveu-se em 2015/17 e centrou-se nos seguintes objetivos:

a) Identificar quais os meios e oportunidades de formação, entretenimento e desenvolvimento pessoal que as cidades oferecem aos grupos com necessidades especiais;

b) Identificar como fomentam as cidades, em termos de planeamento, de ordenamento do espaço físico, respostas que favoreçam o acesso dos cidadãos com necessidades especiais aos espaços de convívio, de lazer, de equipamentos e serviços comunitários;

c) Indagar como são desenvolvidas as políticas locais de fomento da 
coesão social, por forma a incluir socialmente todos, em particular os cidadãos com necessidades especiais.

\subsection{Metodologia utilizada}

A organização deste estudo implicou um conjunto de métodos que possibilitam conhecer, conforme os objetivos estabelecidos, as políticas inclusivas das cidades e refletir sobre as suas implicações na qualidade de vida das pessoas com deficiência, procurando caracterizar as boas práticas de inclusão social.

Pretendeu-se estudar as políticas socioeducativas, tendo por referência vários lugares distintos e vários municípios. Interessa comparar essas realidades para se poder compreender melhor as suas semelhanças e as suas diferenças. Neste quadro, o enfoque da investigação comparada revelou-se o mais pertinente pois, no caso presente, temos realidades que merecem ser confrontadas, havendo interesse e significado educativo em estudar as semelhanças e as diferenças dos casos que se investigam. A investigação realizada caracterizou-se por realizar um estudo descritivo, de natureza qualitativa, enquadrado por uma metodologia comparativista e que enforma o que a literatura convencionou designar por estudo de caso.

Utilizaram-se instrumentos e técnicas em uso habitual neste tipo de estudos, tais como o inquérito por questionário, as entrevistas e a análise documental. $\mathrm{O}$ inquérito por questionário foi o método utilizado para a recolha de informação a um grupo alargado de informantes, 57 cidades que, à data de 2016, pertenciam à AICE, procurando aferir a perceção dos responsáveis sobre as condições de inclusão que a cidade oferece às pessoas com deficiência.

O referido questionário, que foi validado por um comité de 5 especialistas, é constituído por 77 itens e foi respondido por responsáveis de 31 cidades (54\% de retorno) e centrou-se em três grandes temas: a) o fenómeno da exclusão e da inclusão, b) o acesso das pessoas com deficiência aos recursos e aos serviços da cidade, c) os fundamentos das políticas inclusivas. $\mathrm{O}$ inquérito por questionário foi administrado por via eletrónica e a recolha das respostas levou cerca de 30 dias.

A partir dos resultados obtidos com a aplicação do questionário foi possível listar as cidades conforme as perceções acerca das suas condições para 
a inclusão e selecionar duas das que obtiveram melhores scores, ou seja, na opinião dos respondentes terão melhores condições de inclusão para as pessoas com deficiência. Essas cidades foram unidades de estudo onde se recolheu um conjunto de informação, através da análise documental e das entrevistas a um conjunto de informantes privilegiados dos municípios e da cidade (vereadores, técnicos municipais, cidadãos com deficiência e dirigentes de associações locais ligados à problemática) para se obterem informações mais detalhadas e mais aprofundadas que permitam identificar as políticas, as medidas e as ações de inclusão social numa dada unidade de estudo. Deste modo, foi possível definir os critérios que definem as «boas práticas» na construção de cidades mais inclusivas.

\subsection{Principais resultados}

Através da análise e tratamento dos resultados do inquérito por questionário foi possível construir uma escala ordenada, conforme a perceção que os respondentes expressam acerca do potencial inclusivo, não tendo em conta as pessoas com deficiência e a resposta às suas necessidades (Gráfico 1). Foi possível construir essa escala ordenada, aplicando os parâmetros definidos, o que permitiu uma ordenação da cidade que obteve maior percentagem de pontos para a que obteve a menor, em que a diferença e a amplitude de valores oscila da que obteve o valor mais elevado - um valor de $79,4 \%$ - até à que obteve o valor mais baixo com $20,5 \%$. A percentagem alcançada por cada cidade foi encontrada entre a pontuação obtida e a diferença para a pontuação máxima em cada um dos parâmetros, ou seja, a cidade que obteve maior percentagem ainda ficou a $20,6 \%$ da pontuação desejável e a que obteve menor pontuação ficou aquém do desejável $79,4 \%$. São sete as cidades que estão num intervalo entre os $80 \%$ e os $60 \%$, treze as cidades que estão no intervalo entre os $50 \%$ e os $60 \%$, seis cidades que estão na casa dos $40 \%$, quatro na casa dos $30 \%$ e uma na casa dos $20 \%$.

Se for traçado um quadro de análise, a partir da média poder-se-á concluir, conforme os resultados que vinte e duas cidades, ou melhor, os seus gestores revelam uma perceção moderada de que alguma coisa se está a fazer para influenciar a inclusão e nove têm uma perceção mais contida ou mais 
cautelosa de que ainda se está muito aquém desse desígnio. Mais de 50\% das cidades inquiridas reconhecem que estão a fazer esforços para a inclusão, mas só $22 \%$ das cidades se situam em scores entre os $60 \%$ e os $80 \%$ dos itens medidos.

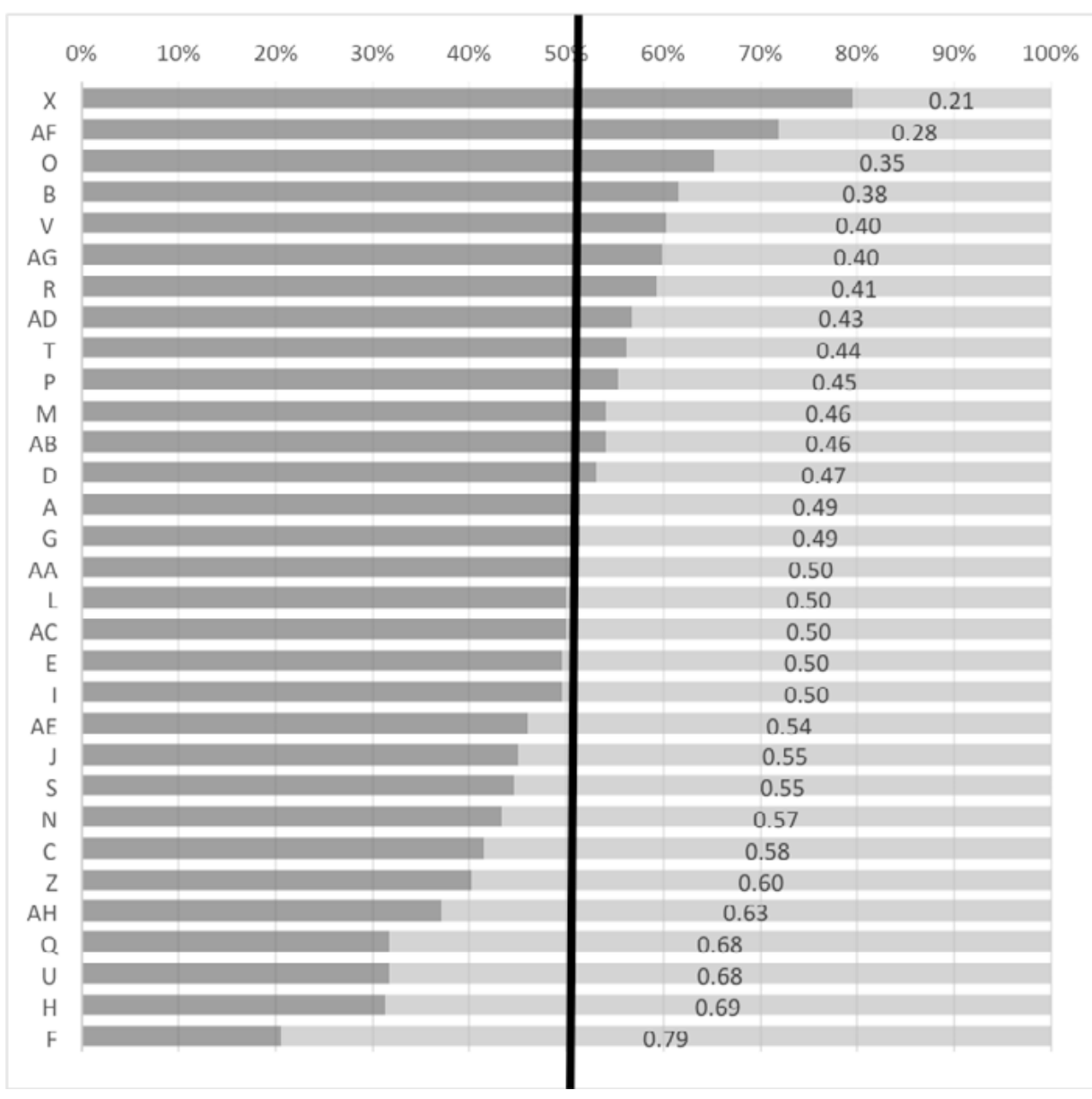

Gráfico 1. Escala ordenada das cidades conforme o potencial de inclusão.

Pelos scores que se obtiveram no questionário, podem dividir-se os processos de inclusão em três tipos padrão. As cidades que estão ainda num estádio embrionário, que estão agora a despertar para o problema mas não têm trabalho relevante no terreno; as cidades que estão num estádio de arranque das ações e das medidas inclusivas, mas que ainda necessitam de percorrer todo um caminho de concretização mais consistente; e, finalmente, as cidades que estão num estádio de desenvolvimento, que já arrancaram, têm trabalho no terreno, está assumido no seu projeto político e de desenvolvimento, têm 
dispositivos e meios que já as distinguem dos estádios anteriores e conseguiram montar um processo de envolvimento ao nível local, das instituições, das entidades, das escolas, das associações de e para as pessoas com necessidades especiais e entendem o trabalho feito como um processo em desenvolvimento que carece de continuidade e de mais meios para progredir.

Para além da análise cidade a cidade foi feita uma análise por categorias de análise, nas 31 cidades estudadas, conforme o quadro 1 . Verifica-se que as cidades têm mostrado maior índice de progressão na educação, na formação e nos projetos que fomentam o convívio social. As áreas intermédias de progresso, onde ainda são necessários mais recursos, mais trabalho articulado e mais meios, designaram-se por «áreas emergentes» e as «áreas fracas»e «muito fracas» são aquelas onde, na grande maioria das cidades, ainda está quase tudo por fazer. Tendo em conta que o conceito de inclusão é um conceito holístico, isso implica que se desenvolvam políticas públicas integradas. As cidades são mais procuradas para viver, precisamente porque aí se encontram respostas para o conjunto das necessidades humanas, ficando evidente, pelos resultados deste estudo, que isso não acontece para as pessoas com diversidade funcional. É de notar que quando comparámos as cidades em que as perceções são mais inclusivas com aquelas em que as perceções são menos inclusivas existem áreas críticas que são comuns aos dois grupos: é o caso da habitação e os planos de acessibilidade universal que parecem ser das áreas mais difíceis e onde se devem empreender mais esforços.

Quadro 1. Análise das áreas fortes e fracas.

\begin{tabular}{|c|c|c|c|}
\hline Áreas Fortes & Áreas Emergentes & Áreas Fracas & Áreas muito fracas \\
\hline Educação e formação & Serviços sociais & Acessibilidades edifícios & $\begin{array}{c}\text { Plano estratégico de } \\
\text { promoção da acessibi- } \\
\text { lidade }\end{array}$ \\
\hline Convívio social & Serviços gerais & Barreiras arquitetónicas & Habitação \\
\hline & Serviços de saúde & Transportes & \\
\hline & Acesso à informação & $\begin{array}{c}\text { Tempos livres, desporto, } \\
\text { cultura }\end{array}$ & \\
\hline & Estudos e diagnóstico & Trabalho & \\
\hline
\end{tabular}




\section{A procura de «boas práticas» na construção de cidades mais inclusivas}

A partir dos dois estudos de casos, de dimensão mais intensiva, que se desenvolveram nas cidades $\mathrm{X}$ e $\mathrm{B},{ }^{2}$ foi possível elencar um conjunto de características que determinam a capacidade que as cidades têm de melhor incluir as pessoas com deficiência, a saber:

1. Cidades muito conscientes da necessidade de promover a inclusão dos grupos mais marginalizados que, para o caso, desenvolvem políticas com uma matriz fortemente social que se reflete nos projetos, nas medidas e ações que são levadas a cabo e que estão em linha com as recomendações para as cidades inclusivas;

2. Apoiam-se muito nos recursos endógenos e promovem processos de liderança que mobilizam a comunidade, conseguindo transformar a realidade para criar melhores condições de vida para os cidadãos em geral e, em particular, para os que têm deficiências;

3. As políticas locais para a promoção da inclusão das pessoas com deficiência não estão desligadas de um quadro mais geral do projeto político para a cidade, com ênfase para as questões educativas e sociais;

4. O motor da mudança é uma forte e clara opção política de curto, médio e longo prazo, com um forte empenho dos atores políticos e de uma articulação com os quadros técnicos, na constante procura de novos meios e de melhores soluções para os múltiplos problemas;

5. A construção das políticas inclusivas fundamenta-se e apoia-se nas relações com as redes internacionais e no desenvolvimento dos projetos socioeducativos que funcionam como estratégia de mobilização para a transformação das realidades, promovendo a adaptabilidade das cidades.

6. Forte relação entre os desígnios políticos e as medidas que se implementam com a alocação de recursos técnicos e financeiros para a concretização dos projetos que se querem levar a cabo;

2. Selecionadas por serem semelhantes em vários parâmetros como o número de habitantes, o número de pessoas com deficiência, o poder de compra, a escolaridade, os beneficiários do subsídio de deficiência e os valores dos orçamentos municipais. 
7. Amplo entendimento relativamente às competências dos municípios, de modo a irem acompanhando o diagnóstico dos problemas e a implementação das soluções, favorecendo de forma gradual o acesso aos serviços e aos recursos da cidade;

8. Amplitude das medidas de política que se vão estendendo às diferentes áreas implicadas na vida independente e autónoma das pessoas com deficiência, ou seja, um entendimento amplo do conceito de inclusão social;

9. No que se refere às políticas empreendidas nas cidades, no sentido de potencializar a inclusão, poder-se-á concluir, pelos dados recolhidos, que é necessário evoluir para políticas sociais mais integradas, em que os processos de decisão sejam sustentados no conhecimento técnico da realidade e da participação efetiva dos próprios interessados, desenvolvendo-se modelos de governança mais abertos e partilhados em termos das decisões;

10. As dificuldades expressas implicam uma maior concertação dos vários níveis de decisão por parte dos organismos públicos do Estado central e dos Municípios, sendo possível, desse modo, encarar com abrangência os diversos domínios que estão implicados nos processos inclusivos.

\section{Conclusões finais}

Retomando o nosso quadro de partida, de que as cidades educadoras teriam maior potencial inclusivo na medida em que poderiam desenvolver estratégias para a construção de cidades mais inclusivas, foi possível tirar algumas conclusões que respondem à relação que se poderá estabelecer entre a cidade educadora e a cidade inclusiva.

A partir do recenseamento dos projetos desenvolvidos nas 31 cidades são nítidas as características que associam as cidades que revelaram maior potencial inclusivo às características próprias de uma cidade educadora, segundo a taxonomia proposta por Trilla Brenet (1999). Primeira característica, a adaptabilidade e o dinamismo, que se revela na capacidade que a 
cidade tem de se adaptar à mudança e às novas necessidades, procurando respostas educativas face às novas realidades sociais, culturais, pobreza, marginalidade, etc.

Segunda característica, a compensação, que se corporiza pelo aumento dos recursos educativos de uma cidade, funcionando como fator de discriminação positiva face a situações como os problemas económicos, as desigualdades, as deficiências, ou seja, através do enriquecimento do meio procura-se compensar as dificuldades. Refere o autor que, deste modo, os territórios podem desempenhar uma função de equidade no caso das pessoas que, por algum motivo, estão em risco social ou de desenvolvimento. Terceira característica, o espaço público, emerge como espaço privilegiado para as aprendizagens informais, para as trocas, para a sociabilidade, para a convivência. É no espaço público que muito do currículo implícito da cidade se desenvolve em múltiplas atividades que ajudam a transmitir conhecimento, valores, tradições e práticas sociais, que são importantes nos processos de pertença e de inclusão na comunidade.

Esta observação foi ainda mais fácil de constatar nas cidades que serviram de estudo de caso, pois nessas duas cidades todos os projetos que visam alterar a qualidade de vida das pessoas com deficiência têm traços de projetos socioeducativos, pois tratam de problemas complexos e visam gerar processos de mudança, de conhecimento e de aprendizagem nos indivíduos. São, por exemplo, todos os projetos de acesso à cultura, à dança, ao teatro, ao desporto, a programação específica dos serviços educativos dos equipamentos municipais, que procuram responder à diversidade funcional dos participantes, são também todas as iniciativas de formação, de sensibilização da comunidade e das famílias, todos os projetos que decorrem da educação inclusiva e educação precoce e que têm relação com o meio envolvente. A educação, nestes casos, é nitidamente uma estratégia de melhorar a vida das comunidades e de as transformar em contextos mais inclusivos. 


\section{Referências}

Alves, M., E Azevedo, N. (2010). (Re)pensando a Investigação em Educação. Em M. Alves, e N. Azevedo, Investigar em Educação Desafios na Construção de Conhecimento e na Formação de Investigadores Num Campo Multi-Referenciado (pp. 1-27). Óbidos: Mariana Gaio Lima e Nair Azevedo.

Balbo, M., Jordán, R., E Simioni, D. (2003). La Ciudad Inclusiva. Santiago do Chile: Nações Unidas.

Bohigas, O. (2013). Ciudad, Urbanismo Y Educación. (Asociación Internacional de Ciudades Educadoras, Entrevistador)

Convenção dos Direitos das Pessoas com Deficiência. (13 de dezembro de 2006). Gabinete de Documentação e Direito Comparado. Obtido em 1 de novembro de 2015, de http://direitoshumanos.gddc.pt/3_7/ IIIPAG3_7_1.htm

Declaração Final do Congresso da Aice (2014). Obtido em 1 de janeiro de 2019, de http://www.edcities.org/wp-content/uploads/2014/11/ Declaración-Congreso-2014-ES DEF.pdf

Declaração de InCheon - educaÇão 2030 (Unesco 2016). Obtido em 23 de janeiro de 2019 de http://www.unesco.org/new/pt/brasilia/about-this-office/single-view/news/education_2030_incheon_declaration_and and framework for_ac/

Declaração de Lisboa Sobre Equidade Educativa (julho de 2015). Obtido em 23 de janeiro de 2019 de http://isec2015lisbon-pt.weebly.com/ declaracao-de-lisboa-sobre-equidade-educativa.html

Del Pozo, J. (2003). Les Polítiques Municipals en Educació. Simposio Internacional: La Millora de Les Oportunitats Educatives en la Societitat en Transformació. Barcelona.

- (2013). O Conceito de «Cidade Educadora» Hoje. Em Educação e Vida Urbana: 20 Anos de Cidades Educadoras (pp. 22-30). Torres Novas: Rede Portuguesa das Cidades Educadoras.

FAuré, E. (1972). La Educación del Futuro. Madrid: Alianza/Unesco.

Fernandes, A. S. (s.d.). Cidade Educadora: Novas Perspectivas das Políticas Educativas. Obtido em 27 de fevereiro de 2014, de https://www. google.com/\#q=CIDADE+EDUCADORA\%3A+NOVAS+PERSPECTIVAS+DAS+POL\%C3\%8DTICAS+EDUCATIVAS

Lorenzo, R. (2005). Discapacidad, Exclusión Social y Ciudadanía. Em J. Tezanos, Tendencias en Exclusión Social y Políticas de Solidariedad (pp. 177-198). Madrid: Editora Sistema. 
Martin, E. (2007). De Las Ciudades Educadoras a Las Ciudades Inclusivas. CEE Participación Educativa, 6, 9-18.

Merino, A. P. (2007). La Ciudad Educa: aportaciones para una política educativa local. Barcelona: Ediciones del Serbal.

Rasteiro, D. (2017) Rutas Para la Inclusión social en Portugal: dos estudios de casos centrados en las políticas locales para las personas con discapacidad. (Tese de Doutoramento). Obtido em 21 de janeiro 2019 de https://comum.rcaap.pt/handle/10400.26/19349

SAntos, M. (2008). A Natureza do Espaço: técnica e tempo, razão e emoção. São Paulo: Edições USP.

SASSAKI, R. (2003). Inclusão - construindo uma sociedade para todos. Rio de Janeiro: WVA.

Teixeira, A. (2015). Mais Poder para as Cidades. Xxi Ter Opinião, 4, 8-11.

Trilla, J. (1999). La Ciudad Educadora. Cuadernos de Pedagogía, n. ${ }^{\circ}$ 278, 44-50.

- (2006). A Educación Non Formal e a Cidade Educadora. Dúas Perspectivas (Unha Analítica e Outra Globalizadora) do Universo da Educación. Revista Galega do Ensino, 24, 199-221. 
